(2) Open Access Full Text Article

REVIEW

\title{
Brentuximab vedotin for relapsed or refractory Hodgkin's lymphoma
}

This article was published in the following Dove Press journal:

Drug Design, Development and Therapy

23 March 2015

Number of times this article has been viewed

\section{Runzhe Chen \\ Baoan Chen}

Department of Hematology and Oncology (Key Department of Jiangsu Medicine), Zhongda Hospital, Medical School, Southeast University, Nanjing, Jiangsu Province, People's Republic of China
Correspondence: Baoan Chen Department of Hematology and Oncology (Key Department of Jiangsu Medicine), Zhongda Hospital, Medical School, Southeast University, Dingjiaqiao 87, Gulou District, Nanjing 210009 , Jiangsu Province, People's Republic of China

Tel +862583272006

Fax +86258327 20II

Email cba8888@hotmail.com
Abstract: Brentuximab vedotin is a promising antibody-drug conjugate (ADC) targeting CD30 of tumor cells. It selectively delivers monomethyl auristatin E (MMAE) into CD30expressing cells and induces tumor cell apoptosis. Various clinical trials have provided evidence that it is effective in relapsed or refractory Hodgkin's lymphoma (HL), and it has also shown its advantages in other CD30-positive lymphomas. In this review, we focus on the structure, mechanisms, and pharmacokinetics of brentuximab vedotin. We also summarize clinical trials with brentuximab vedotin and make recommendations for brentuximab vedotin in the treatment of relapsed or refractory HL.

Keywords: lymphoma, CD30-positive, clinical trials, tumor cells, antitumor effects, monoclonal antibody

\section{Introduction}

Hodgkin's lymphoma (HL) accounts for approximately $30 \%$ of all lymphomas. ${ }^{1}$ On the basis of current clinical advances, due to the development of highly active chemotherapy protocols and the optimization of radiotherapy, patients with newly diagnosed HL have an excellent prognosis after frontline therapy, and their 5 year progression-free survival rate can be as high as $75 \%-80 \%$. ${ }^{2}$ However, curing HL patients who are refractory after salvage chemotherapy and who relapse after autologous hematopoietic stem cell transplantation (auto-SCT) or allogeneic hematopoietic stem cell transplantation (allo-SCT) remains a clinical challenge in view of limited effective treatment, and such patients are rarely cured, having a median overall survival of only 2-3 years. ${ }^{2-5}$

Brentuximab vedotin (SGN-35), a promising antibody-drug conjugate (ADC) that selectively delivers a toxic microtubule-disrupting agent monomethyl auristatin $\mathrm{E}$ (MMAE) into CD30-expressing cells, ${ }^{6}$ was approved by the US Food and Drug Administration (FDA) in 2011..$^{7-10}$ In various clinical trials, brentuximab vedotin has demonstrated efficacy and safety in patients with HL after failure of auto-SCT, or after failure of at least two prior multidrug regimens in HL patients who are not candidates for auto-SCT, and in patients with systemic anaplastic large-cell lymphoma (SALCL) after failure of at least one prior multiagent chemotherapy regimen. ${ }^{11-15}$ In this review, we address the structure, mechanisms, and pharmacokinetics of brentuximab vedotin. We also summarize clinical experiences with brentuximab vedotin and recommend critical strategies of brentuximab vedotin in the treatment of relapsed or refractory HL.

\section{Mechanism, structure, and pharmacokinetics Mechanism}

CD30 is an important therapeutic target for the treatment of malignant lymphomas. ${ }^{16-18}$ It is a member of the tumor necrosis factor (TNF) cell receptor superfamily and is highly 
expressed in a variety of lymphoma subsets, including HL and SALCL. The initial design plan of brentuximab vedotin is just developing a monoclonal antibody targeting CD30. In order to enhance the antitumor effects, a tubulin inhibitor was added to the monoclonal antibody, ${ }^{19}$ and it produced high response rates with an excellent safety profile. ${ }^{20}$ These results led to the approval of brentuximab vedotin for the treatment of patients with CD30-expressing malignancies such as relapsed HL and ALCL. ${ }^{21,22}$ The mechanism of brentuximab vedotin is that binding of the ADC to CD30 on tumor cells initiates internalization of the ADC-CD30 complex with subsequent release of MMAE into the lysosomal compartment, after which MMAE binds to tubulin, thus disrupting the microtubule network and inducing cell cycle arrest and apoptosis. ${ }^{20,23,24}$

\section{Structure}

Brentuximab vedotin is an ADC consisting of the monoclonal antibody cAC10 and the cytotoxic agent MMAE. ${ }^{25}$ cAC10 (SGN-30) is a chimeric anti-CD30 monoclonal antibody that is derived from the fusion of the variable heavy and light region of the murine anti-CD30 antibody AC10, with the constant $\gamma 1$-heavy and $\kappa$-light region of the human immunoglobulin. ${ }^{26} \mathrm{MMAE}$ is a synthetic derivative of dolastatin 10, a cytostatic pseudopeptide isolated from the marine shell-less mollusk Dorabella auricularia. MMAE has the effect of cytostasis, tubulin-dependent GTP hydrolysis, and polymerization. As a result, MMAE has shown significant activity against various hematopoietic tumors by inhibiting the G2/M phases of the cell cycle. ${ }^{19,25,27}$ The points of MMAE attachment on cAC10 scaffold are $-\mathrm{SH}$ groups of cysteine residues produced by reduction of the interchain disulfide bonds. The linker includes a thiolreactive maleimidocaproyl spacer, the dipeptide valine-citrulline linker, and a self-immolative $p$-aminobenzylcarbamate spacer. The peptide-based linker provides a highly stable bond between the antibody and the cytotoxic compound under physiologic conditions while it facilitates the rapid and efficient drug cleavage on internalization of the ADC by the target tumor cell. ${ }^{25}$

\section{Pharmacokinetics}

According to research, the area under the concentrationtime curve (AUC) of brentuximab vedotin can be increased relative to its dosage and will not accumulate with repeated dosing. Preclinical research showed that the elimination halflife of brentuximab vedotin in mice was approximately 5 days and the maximum tolerated dose was $>30 \mathrm{mg} / \mathrm{kg} .{ }^{28}$

\section{Preclinical studies}

In models of HL, the chimeric monoclonal antibody cAC10 has been shown to promote arrest of tumor cell growth and cause DNA fragmentation. Cross-linking cAC10 suppressed proliferation in a variety of Hodgkin and ALCL cell lines. When combined with chemotherapy agents, brentuximab vedotin could enhance the efficacy of these agents. ${ }^{26}$

\section{Clinical studies}

The efficacy of brentuximab vedotin in the treatment of relapsed and refractory HL has been investigated in several clinical trials on register (Table 1).

\section{Phase I}

In a Phase I, open-label, multicenter dose-escalation study, Younes et $\mathrm{al}^{29}$ administered brentuximab vedotin at a dose of $0.1-3.6 \mathrm{mg} / \mathrm{kg}$ of body weight every 3 weeks to 45 patients with relapsed or refractory CD30-positive hematologic cancers, including HL; the results showed that the maximum tolerated dose (MTD) was $1.8 \mathrm{mg} / \mathrm{kg}$, administered every 3 weeks. However, another Phase I study conducted by Fanale et al ${ }^{30}$ demonstrated that the MTD for patients with relapsed or refractory $\mathrm{HL}$ and SALCL was $1.2 \mathrm{mg} / \mathrm{kg}$. In a Phase I/II study carried out in Japan, brentuximab vedotin was given intravenously on day 1 of each 21 -day cycle up to 16 cycles. In the Phase I part of a dose-escalation design, three patients per cohort were treated at doses of 1.2 and $1.8 \mathrm{mg} / \mathrm{kg}$, and the study confirmed that brentuximab vedotin has an acceptable safety profile and promising antitumor activity in the Japanese population. ${ }^{6}$

\section{Phase II}

There have been three Phase II clinical trials of brentuximab vedotin in the treatment of relapsed/refractory HL. Gopal et $\mathrm{al}^{31}$ evaluated brentuximab vedotin in $25 \mathrm{HL}$ patients, and patients received 1.2 or $1.8 \mathrm{mg} / \mathrm{kg}$ of brentuximab vedotin intravenously every 3 weeks. Among 24 evaluable patients, overall and complete response rates were $50 \%$ and $38 \%$, respectively. Median time to response was 8.1 weeks, median progression-free survival was 7.8 months, and the median overall survival was not reached. Their results supported the potential efficacy of brentuximab vedotin for patients with HL relapsing after allo-SCT.

In another multinational, open-label, Phase II study, the efficacy and safety of brentuximab vedotin were evaluated in 102 patients with relapsed or refractory HL after autoSCT, and the patients were treated with brentuximab vedotin $1.8 \mathrm{mg} / \mathrm{kg}$ by intravenous infusion every 3 weeks. The results 


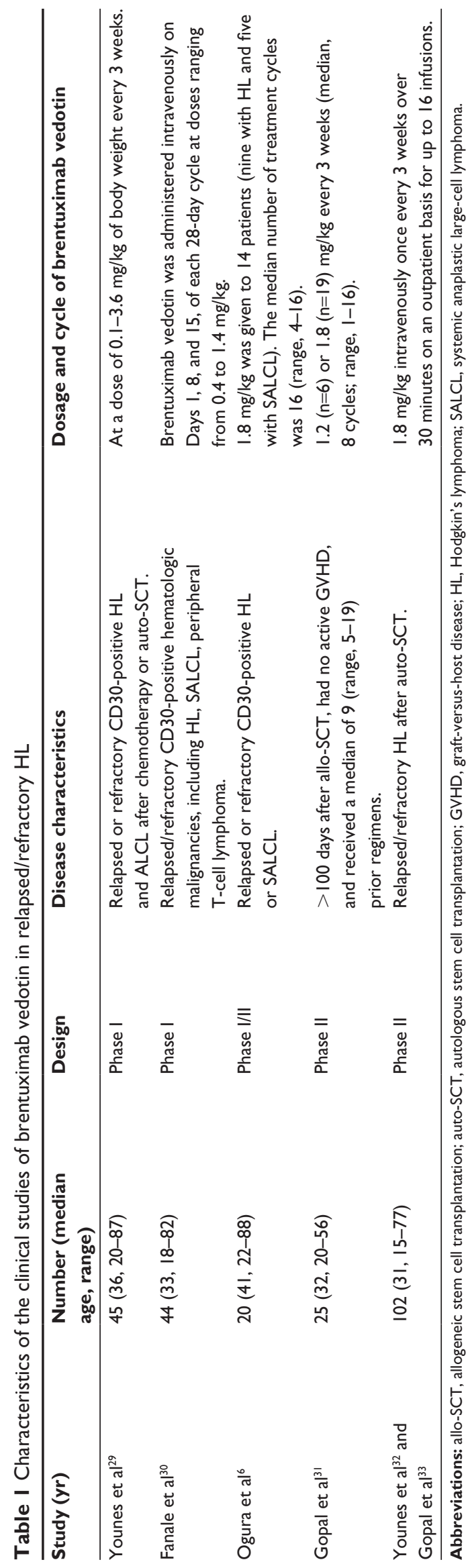

demonstrated that the overall response rate (ORR) was 75\% with complete remission (CR) in $34 \%$ of patients. The median progression-free survival time for all patients was 5.6 months, and the median duration of response for those in CR was 20.5 months. The study also indicated that younger age, good performance status, and lower disease burden at baseline were characteristic of patients who achieved a CR and were favorable prognostic factors for overall survival. ${ }^{32,33}$

In the Phase II part of the study conducted by Ogura et $\mathrm{al}^{6}$ in Japan, a dose of $1.8 \mathrm{mg} / \mathrm{kg}$ was given to nine patients with HL. The median number of treatment cycles was 16 (range, 4-16). Six patients (67\%) achieved an objective response with $56 \%$ of complete response rate, so these results indicated that brentuximab vedotin has a promising antitumor activity in the Japanese population.

\section{Use in other diseases}

Several clinical trials have also been conducted to investigate the role of brentuximab vedotin in other diseases in addition to HL.

In a Phase II trial conducted by Pro et al, ${ }^{34} 58$ patients with SALCL and recurrent disease after at least one prior therapy received brentuximab vedotin $1.8 \mathrm{mg} / \mathrm{kg}$ intravenously every 3 weeks over 30 minutes as an outpatient infusion. Fifty patients (86\%) achieved an objective response, 33 patients (57\%) achieved CR, and 17 patients (29\%) achieved a partial remission (PR). The median durations of overall response and CR were 12.6 and 13.2 months, respectively.

Another Phase II study evaluated the efficacy and safety of brentuximab vedotin in relapsed/refractory $\mathrm{CD} 30+$ nonHodgkin's lymphomas (NHL). The analysis included patients with peripheral T-cell lymphomas (PTCLs; $n=35$ ), specifically angioimmunoblastic T-cell lymphoma (AITL; $n=13$ ) and PTCL not otherwise specified ( $\mathrm{n}=22$ ), and in this study brentuximab vedotin showed antitumor activity in patients with relapsed PTCL, particularly AITL. ${ }^{35}$

Jacobsen et $\mathrm{al}^{36}$ studied the role of brentuximab vedotin in 78 patients, including 49 diffuse large B-cell lymphoma (DLBCL) patients and 19 with other B-cell NHLs, and ORR was $44 \%$ for DLBCL, and patients with other B-cell lymphomas also responded: one $\mathrm{CR}$, two PRs of six with gray zone, one CR of six with primary mediastinal B-cell, and one CR of three with posttransplant lymphoproliferative disorder.

\section{Adverse effect}

Brentuximab vedotin is reported to have been generally well tolerated by patients; ${ }^{6,31-36}$ however, adverse effects also occurred, according to reports, but they were considered 
manageable. ${ }^{37,38}$ Common adverse effects included peripheral neuropathy, fatigue, nausea, arthralgia, and pyrexia. ${ }^{39-41}$ Neutropenia, thrombocytopenia, diarrhea, hyperglycemia, cytomegalovirus infection, peripheral sensory neuropathy, tumor lysis syndrome, Stevens-Johnson syndrome, and progressive multifocal leukoencephalopathy have also been reported with its use. . $31,32,38,39,41^{-1}$

\section{Conclusion and future directions}

Brentuximab vedotin is an effective therapy for patients with relapsed or refractory HL. Binding of the ADC to CD30 on tumor cells induces tumor cell cycle arrest, and apoptosis is its main mechanism. In clinical trials, brentuximab vedotin shows its advantages, and it is a very promising agent in the treatment of relapsed or refractory HL, though some side effects still occurred in patients, according to clinical studies. In the future, brentuximab vedotin may become first line in dealing with relapsed/refractory CD30 positive malignancies; however, clinical trials with larger samples need further investigations; the efficacy of brentuximab vedotin combined with chemotherapy or radiotherapy should also be evaluated in clinical trials, and methods of decreasing the toxicity of brentuximab vedotin need further study.

\section{Acknowledgments}

This work was supported by the National Natural Science Foundation of People's Republic of China (Grant number 81170492, 81370673), National High Technology Research and Development Program 863 of People's Republic of China (Grant number 2012AA022703), National Key Basic Research Program 973 of People's Republic of China (Grant number 2010CB732404), Key Medical Projects of Jiangsu Province (Grant number BL2014078), and Key Discipline of Jiangsu Province (2011-2015).

\section{Disclosure}

The authors report no conflicts of interest in this work.

\section{References}

1. Younes A. Novel treatment strategies for patients with relapsed classical Hodgkin lymphoma. Hematology. 2009:507-519.

2. Eichenauer DA, Boll B, Diehl V. Pharmacotherapy of Hodgkin lymphoma: standard approaches and future perspectives. Expert Opin Pharmacother. 2014;15(8):1139-1151.

3. Zinzani PL, Viviani S, Anastasia A, et al. Brentuximab vedotin in relapsed/refractory Hodgkin's lymphoma: the Italian experience and results of its use in daily clinical practice outside clinical trials. Haematologica. 2013;98(8):1232-1236.

4. Dinner S, Advani R. Targeted therapy in relapsed classical Hodgkin lymphoma. J Natl Compr Canc Netw. 2013;11(8):968-976.
5. Garciaz S, Coso D, Peyrade F, et al. Brentuximab vedotin followed by allogeneic transplantation as salvage regimen in patients with relapsed and/or refractory Hodgkin's lymphoma. Hematol Oncol. 2014;32(4):187-189. doi:10.1002/hon.2119.

6. Ogura M, Tobinai K, Hatake K, et al. Phase I/II study of brentuximab vedotin in Japanese patients with relapsed or refractory CD30-positive Hodgkin's lymphoma or systemic anaplastic large-cell lymphoma. Cancer Sci. 2014;105(7):840-846.

7. Younes A. Brentuximab vedotin for the treatment of patients with Hodgkin lymphoma. Hematol Oncol Clin North Am. 2014;28(1):27-32.

8. Deng C, Pan B, O'Connor OA. Brentuximab vedotin. Clin Cancer Res. 2013;19(1):22-27.

9. Devita MD, Evens AM, Rosen ST, Greenberger PA, Petrich AM. Multiple successful desensitizations to brentuximab vedotin: a case report and literature review. J Natl Compr Canc Netw. 2014;12(4):465-471.

10. Rothe A, Sasse S, Goergen H, et al. Brentuximab vedotin for relapsed or refractory CD30+ hematologic malignancies: the German Hodgkin Study Group experience. Blood. 2012;120(7):1470-1472.

11. Macalalad AR, McAuliffe M, Yang H, et al. The epidemiology and targeted therapies for relapsed and refractory CD30+ lymphomas. Curr Med Res Opin. 2015:1-32. Epub February 9, 2015.

12. Kharfan-Dabaja MA, Hamadani M, Sibai H, Savani BN. Managing Hodgkin lymphoma relapsing after autologous hematopoietic cell transplantation: a not-so-good cancer after all! Bone Marrow Transplant. 2014;49(5):599-606.

13. Gopal AK, Bartlett NL, Forero-Torres A, et al. Brentuximab vedotin in patients aged 60 years or older with relapsed or refractory CD30positive lymphomas: a retrospective evaluation of safety and efficacy. Leuk Lymphoma. 2014;55(10):2328-2334.

14. Chihara D, Oki Y. Brentuximab vedotin for treatment of systemic T-cell lymphoma. Expert Opin Biol Ther. 2014;14(10):1519-1526.

15. Bradley AM, Devine M, DeRemer D. Brentuximab vedotin: an antiCD30 antibody-drug conjugate. Am J Health Syst Pharm. 2013;70(7): 589-597.

16. Hu S, Xu-Monette ZY, Balasubramanyam A, et al. CD30 expression defines a novel subgroup of diffuse large B-cell lymphoma with favorable prognosis and distinct gene expression signature: a report from the International DLBCL Rituximab-CHOP Consortium Program Study. Blood. 2013;121(14):2715-2724.

17. Pro B, Perini GF. Brentuximab vedotin in Hodgkin's lymphoma. Expert Opin Biol Ther. 2012;12(10):1415-1421.

18. Deutsch YE, Tadmor T, Podack ER, Rosenblatt JD. CD30: an important new target in hematologic malignancies. Leuk Lymphoma. 2011;52(9): $1641-1654$.

19. Tsang V. Brentuximab vedotin in hodgkin lymphoma and anaplastic large cell lymphoma. J Adv Pract Oncol. 2012;3(3):184-190.

20. Bhatt S, Ashlock BM, Natkunam Y, et al. CD30 targeting with brentuximab vedotin: a novel therapeutic approach to primary effusion lymphoma. Blood. 2013;122(7):1233-1242.

21. Kumar A, Younes A. Role of CD30 targeting in malignant lymphoma. Curr Treat Options Oncol. 2014;15(2):210-225.

22. Diefenbach CS, Leonard JP. Targeting CD30 in Hodgkin lymphoma: antibody-drug conjugates make a difference. Am Soc Clin Oncol Educ Book. 2012:162-166.

23. Magge RS, DeAngelis LM. The double-edged sword: neurotoxicity of chemotherapy. Blood Rev. Epub December 3, 2014. doi:10.1016/j. blre.2014.09.012.

24. Gualberto A. Brentuximab vedotin (SGN-35), an antibody-drug conjugate for the treatment of CD30-positive malignancies. Expert Opin Investig Drugs. 2012;21(2):205-216.

25. Vaklavas C, Forero-Torres A. Safety and efficacy of brentuximab vedotin in patients with Hodgkin lymphoma or systemic anaplastic large cell lymphoma. Ther Adv Hematol. 2012;3(4):209-225.

26. Ansell SM. Brentuximab vedotin. Blood. 2014;124(22):3197-3200.

27. Nagai H. Recent advances in Hodgkin lymphoma: interim PET and molecular-targeted therapy. Jpn J Clin Oncol. Epub December 10, 2014. doi:10.1093/jjco/hyu204. 
28. Minich SS. Brentuximab vedotin: a new age in the treatment of Hodgkin lymphoma and anaplastic large cell lymphoma. Ann Pharmacother. 2012;46(3):377-383.

29. Younes A, Bartlett NL, Leonard JP, et al. Brentuximab vedotin (SGN-35) for relapsed CD30-positive lymphomas. N Engl J Med. 2010;363(19): 1812-1821.

30. Fanale MA, Forero-Torres A, Rosenblatt JD, et al. A phase I weekly dosing study of brentuximab vedotin in patients with relapsed/ refractory CD30-positive hematologic malignancies. Clin Cancer Res. 2012;18(1):248-255.

31. Gopal AK, Ramchandren R, O'Connor OA, et al. Safety and efficacy of brentuximab vedotin for Hodgkin lymphoma recurring after allogeneic stem cell transplantation. Blood. 2012;120(3):560-568.

32. Younes A, Gopal AK, Smith SE, et al. Results of a pivotal phase II study of brentuximab vedotin for patients with relapsed or refractory Hodgkin's lymphoma. J Clin Oncol. 2012;30(18):2183-2189.

33. Gopal AK, Chen R, Smith SE, et al. Durable remissions in a pivotal phase 2 study of brentuximab vedotin in relapsed or refractory Hodgkin lymphoma. Blood. Epub December 24, 2014. doi:10.1182/blood-201408-595801.

34. Pro B, Advani R, Brice P, et al. Brentuximab vedotin (SGN-35) in patients with relapsed or refractory systemic anaplastic large-cell lymphoma: results of a phase II study. J Clin Oncol. 2012;30(18):2190-2196.
35. Horwitz SM, Advani RH, Bartlett NL, et al. Objective responses in relapsed T-cell lymphomas with single-agent brentuximab vedotin. Blood. 2014;123(20):3095-3100.

36. Jacobsen ED, Sharman JP, Oki Y, et al. Brentuximab vedotin demonstrates objective responses in a phase 2 study of relapsed/refractory DLBCL with variable CD30 expression. Blood. Epub January 13, 2015. doi:10.1182/blood-2014-09-598763.

37. Forero-Torres A, Fanale M, Advani R, Bartlett NL, et al. Brentuximab vedotin in transplant-naive patients with relapsed or refractory Hodgkin lymphoma: analysis of two phase I studies. Oncologist. 2012;17(8): 1073-1080.

38. Newland AM, Li JX, Wasco LE, Aziz MT, Lowe DK. Brentuximab vedotin: a CD30-directed antibody-cytotoxic drug conjugate. Pharmacotherapy. 2013;33(1):93-104.

39. Lai CM, Horowitz S. Brentuximab vedotin: treatment role for relapsed refractory systemic anaplastic large-cell lymphoma. Expert Rev Hematol. 2013;6(4):361-373.

40. Yang QM, Hong JY, Ko YH, et al. Brentuximab vedotin for relapsed or refractory CD30+ Hodgkin lymphoma: a multicenter analysis from Asia. Onco Targets Ther. 2014;7:1717-1722.

41. Thyss A, Saada E, Gastaud L, Peyrade F, Re D. Hodgkin's lymphoma in older patients: an orphan disease? Mediterr J Hematol Infect Dis. 2014; 6(1):e2014050.

\section{Publish your work in this journal}

Drug Design, Development and Therapy is an international, peerreviewed open-access journal that spans the spectrum of drug design and development through to clinical applications. Clinical outcomes, patient safety, and programs for the development and effective, safe, and sustained use of medicines are a feature of the journal, which

\section{Dovepress}

has also been accepted for indexing on PubMed Central. The manuscript management system is completely online and includes a very quick and fair peer-review system, which is all easy to use. Visit http://www.dovepress.com/testimonials.php to read real quotes from published authors.

Submit your manuscript here: http://www.dovepress.com/drug-design-development-and-therapy-journal 